\title{
Gender differences in recognition memory for faces and cars: Evidence for the interest hypothesis
}

\author{
STUART J. MCKELVIE, LIONEL STANDING, DENISE ST. JEAN, and JAMES LAW \\ Bishop's University, Lennoxville, Quebec, Canada
}

\begin{abstract}
Two experiments investigated gender differences in recognition memory for faces and cars. Stimuli were line drawings of cars and of adult men and women (Experiment 1) and photographs of real cars and of real boys and girls (Experiment 2). In both experiments, performance was better on faces than on cars. Regarding recognition memory for men's faces, in Experiment 1, men's scores were higher than women's scores. However, in Experiment 2, men recognized more cars than did women, and women recognized more children than did men. Results are generally consistent with the hypothesis that memory reflects male and female interest in, and/or differential familiarity for, different kinds of material.
\end{abstract}

Peer effects have been found in recognition memory for faces. Research shows that people are generally more accurate on own-race and gender faces than on other-race and gender faces (Bothwell, Brigham, \& Malpass, 1989; McKelvie, 1981; Shapiro \& Penrod, 1986). However, the gender effect is more reliable for women than for men, and women perform better than men on faces of children, leading McKelvie (1981) to propose that gender differences may be mediated by differential interest. To test this hypothesis, he suggested that researchers might investigate memory for material expected to be of particular interest to men and to women.

Recently, in a developmental study of children and adults, Davies and Robertson (1993) invoked the interest hypothesis to account for their findings that males clearly recognized more photographs of automobiles than did females, whereas females tended to recognize more female faces than did males. Experiment 1 of the present study was also designed to compare memory for faces and cars with memory for adult men and women. However, male faces were included and pictures were shown in the form of line drawings to test the generality of the automobile superiority effect for males.

\section{EXPERIMENT 1}

\section{Method}

Subjects. Participants were 15 male and 15 female undergraduates who were not psychology students and who were paid for their participation.

Materials. Stimuli consisted of 160 black-and-white slide photographs of line drawings of 80 faces ( 40 men, 40 women; see McKelvie, 1981, Experiments 4 and 5) and 80 cars. They were composed by two artists who included sufficent detail to render the stimuli distinguishable. However, the drawings did not represent particular people or makes of cars. Half of the faces ( 20 men, 20 women) and half of the cars were allo-

Send reprint requests to Stuart J. McKelvie, Department of Psychology, Bishop's University, Lennoxville, PQ, Canada J1M $1 Z 7$. cated at random to the presentation set, and all stimuli constituted the test set. For this purpose, they were paired randomly, with the restriction that each stimulus appear beside another from the same class.

Procedure. The subjects were tested in a laboratory in small groups. During Session 1, they were shown each of the $\mathbf{4 0}$ faces or cars for $5 \mathrm{sec}$ and instructed to memorize the material for a test $48 \mathrm{~h}$ later. During this test, the 80 pairs were shown for $10 \mathrm{sec}$, during which the subjects recorded whether the original picture was on the left or the right.

\section{Results}

A $2 \times 2$ (gender of subject $\times$ materials) analysis of variance (ANOVA) was conducted on the number of correct choices. The interaction did not approach significance $[F(1,28)=0.65, p>.20]$, but performance was higher on faces than on cars $[F(1,28)=33.40, p<.01$, see Table 1]. A second $2 \times 2$ (gender of subject $\times$ gender of face) ANOVA showed that subjects recognized more female than male faces $[F(1,28)=33.51, p<.01]$. However, this effect was qualified by a significant interaction $[F(1,28)=14.31, p<.01]$, showing that the female face superiority effect was greater for women than for men (see Table 1). Furthermore, men's recognition memory for men's faces was better than women's $[t(18)=2.11$, $p=.025]$.

Table 1

Mean Number of Correct Forced-Choice Recognition Memory Choices in Experiments 1 and 2

\begin{tabular}{|c|c|c|c|c|c|c|c|c|c|}
\hline \multirow[b]{2}{*}{ Subjects } & \multirow[b]{2}{*}{$n$} & \multicolumn{2}{|c|}{$\begin{array}{l}\text { Male } \\
\text { Faces }\end{array}$} & \multicolumn{2}{|c|}{$\begin{array}{c}\text { Female } \\
\text { Faces }\end{array}$} & \multicolumn{2}{|c|}{ Faces } & \multicolumn{2}{|c|}{ Cars } \\
\hline & & $M$ & $S D$ & $M$ & $S D$ & $M$ & $S D$ & $M$ & $S D$ \\
\hline \multicolumn{10}{|c|}{ Experiment 1} \\
\hline Men & 15 & 17.7 & 1.6 & 18.3 & 1.4 & 35.9 & 2.6 & 33.5 & 2.3 \\
\hline Women & 15 & 16.1 & 1.6 & 19.0 & 0.9 & 35.1 & 2.0 & 31.7 & 2.3 \\
\hline \multicolumn{10}{|c|}{ Experiment 2} \\
\hline Men & 10 & 15.5 & 0.8 & 16.4 & 0.8 & 32.0 & 1.4 & 31.3 & 1.1 \\
\hline Women & 10 & 17.7 & 0.5 & 18.5 & 0.3 & 36.2 & 0.8 & 29.9 & 1.2 \\
\hline
\end{tabular}

Note-Maximum scores were 20 for male and for female faces and $\mathbf{4 0}$ for cars; chance performance was 10 and 20 , respectively. 


\section{Discussion}

Previous research has favored a stronger own-gender effect for women than for men (Davies \& Robertson, 1993; McKelvie, 1981). Here, the general superiority effect for women's over men's faces was greater for women than for men, but women did not recognize more women's faces than did men. However, the present own-gender effect for men has been reported previously (Shapiro \& Penrod, 1986), and occurred as a trend in previous work with the same line drawings (McKelvie, 1981, Experiments 4 and 5).

As did Davies and Robertson (1993), we found that faces were recognized better than cars, but our data did not demonstrate their finding of male superiority on cars. One reason may be that the car line drawings were not sufficiently realistic. Since Davies and Robertson used photographs of real people and cars, we adopted this procedure in Experiment 2 . In addition, to provide a stimulus that was expected to appeal specifically to the interest of women, faces of children were used. It was predicted that men and women would perform relatively better on cars and on faces, respectively.

\section{EXPERIMENT 2}

\section{Method}

Subjects. Two new groups of 10 male and 10 female undergraduates volunteered as subjects.

Materials and Procedure. The experimental faces belonged to 80 children, 6-11 years old (40 males, 40 females), who were photographed at a local elementary school. The pictures of 80 cars were taken at a local intersection. As before, the stimuli were split into presentation and test sets, with equal numbers of cars and faces, and of male and female faces.

Again, the subjects were shown the 80 presentation stimuli for $10 \mathrm{sec}$ each and then returned for the two-alternative forced-choice recognition memory test $48 \mathrm{~h}$ later.

\section{Results and Discussion}

As in Experiment 1, the $2 \times 2$ (gender of subject $\times$ materials) ANOVA showed that performance was better on faces than on cars $[F(1,18)=8.43, p<.01$; see Table 1]. However, there was an interaction between the variables $[F(1,18)=6.10, p<.01]$, indicating that the effect of materials was confined to women (see Table 1). In fact, individual comparisons showed that women recognized more children's faces than did men $[t(18)=$ $7.00, p<.01$ ], whereas men recognized more cars than did women $[t(18)=2.29, p<.025]$. In contrast to Experiment 1 , the ANOVA on faces alone showed only that women performed better than men $[F(1,18)=11.39$, $p<.01]$. There was no interaction $(F<1)$.

The results of Experiment 2 agreed with those of Davies and Robertson (1993) in demonstrating a relative superiority of women on children's faces and of men on cars. Together, these studies provide support for the interest hypothesis (McKelvie, 1981). However, as Davies and Robertson indicate, it is not clear how interest mediates recognition memory. McKelvie suggested that task performance was determined by initial attention and viewing strategies reflecting interests created by differential exposure and social conditioning. However, Davies and Robertson observe that varying levels of knowledge between groups may contribute to the gender effect. Work on the effects of expertise is generally consistent with this suggestion. Recognition memory is higher for experts than for novices for domain-relevant materials such as dogs' faces (Diamond \& Carey, 1986), birds (Peeck \& Zwarts, 1983), and handwriting (Bruyer \& Crispeels, 1992).

To account for the present results, future researchers might investigate gender differences in processing strategies with different kinds of material. In addition, although the effects of interest (motivation) and knowledge (expertise) are difficult to disentangle (Shepherd, 1981), their contributions might be assessed by measuring the former and manipulating the latter via systematic exposure. This approach has met with some success in studies of the race effect, for which training has improved recognition memory performance on faces of other races (Goldstein \& Chance, 1985; Malpass, 1981).

\section{REFERENCES}

Bothwell, R. K., Brigham, J. C., \& Malpass, R. S. (1989). Crossracial identification. Personality \& Social Psychology Bulletin, 15, 19-25.

Bruyer, R., \& CRISPEels, G. (1992). Expertise in person recognition. Bulletin of the Psychonomic Society, 30, 501-504.

DAvies, G., \& RoBERTSON, N. (1993). Recognition memory for automobiles: A developmental study. Bulletin of the Psychonomic Society, 31, 103-106.

Diamond, R., \& CAREY, S. (1986). Why faces are and are not special: An effect of expertise. Journal of Experimental Psychology: General, 115, 107-117.

Goldstein, A. G., \& Chance, J. E. (1985). Effects of training on Japanese face recognition: Reduction of the other-race effect. Bulletin of the Psychonomic Society, 23, 211-214.

Malpass, R. S. (1981). Training in face recognition. In G. Davies, H. Ellis, \& J. Shepherd (Eds.), Perceiving and remembering faces (pp. 271-285). New York: Academic Press.

MCKelvie, S. J. (1981). Sex differences in memory for faces. Journal of Psychology, 107, 109-125.

Peeck, J., \& ZWARTS, J. (1983). Recognition memory for pictures of birds in relation to bird-watching skill. American Journal of Psychology, 96, 553-566.

Shapiro, P. N., \& Penrod, S. (1986). Meta-analysis of facial identification studies. Psychological Bulletin, 100, 139-156.

SHEPHERD, J. (1981). Social factors in face recognition. In G. Davies, H. Ellis, \& J. Shepherd (Eds.), Perceiving and remembering faces (pp. 55-79). New York: Academic Press.

(Manuscript received May 6, 1993.) 